\title{
Cosmovisión e identidad de las cofradías de Izalco y su relación con las condiciones socioeconómicas de sus participantes
}

\section{World View and identity at the cofradías (religious brotherhoods) of Izalco and their relation to the socioeconomic conditions of their participants}

\section{ISSN 2071-8748 \\ E-ISSN 2218-3345 \\ (c) (1) (2)}

DOI: https://doi.org/10.5377/entorno.v0i68.8450

URI : http://hdl.handle.net/11298/1130

\section{Resumen}

La presente investigación tuvo por objetivo identificar la relación que existe entre la cosmovisión e identidad de las cofradías de Izalco con las condiciones socioeconómicas de sus participantes. Se implementó el método cualitativo con un enfoque etnográfico a través del cual se realizó un acercamiento a la comunidad, el cual permitió conocer el sistema económico que predomina en las cofradías, así como también la cosmovisión de los sujetos que participan en ellas.

Los hallazgos de campo evidenciaron el apego de los participantes hacia las raíces indígenas presentes en su identidad cultural, las cuales hacen posible la pervivencia de la tradición de las cofradías, conservando el sistema
Georgina Sulamita Ordoñez-Valle ORCID: 0000-0003-1527-5739 Universidad Tecnológica de El Salvador geor01_valle@yahoo.com

Recibido: 11 de septiembre 2019 Aprobado: 2 de noviembre 2019

\section{Abstract}

The aim of this investigation was to identify the existing relationship between the world view and identity of the cofradías (religious brotherhoods) in Izalco with the socioeconomic conditions of their participants. The qualitative method with an ethnographic approach was implemented; through this, an approach to the community permitted to learn about the predominating economic system at the cofradías, as well as the world view of the individuals who participate in them.

The field findings showed evidence about the bond of the participants to the indigenous roots present in their cultural identity, which made the survival of the tradition of the cofradías, thus preserving the economic

1 Estudiante de la Licenciatura en Antropología, UTEC. 
económico basado en el don a través del cual aseguran su sobrevivencia.

\section{Palabras clave}

Cofradías - Izalco, El Salvador - aspectos socioeconómicos. Identidad cultural - Izalco, El Salvador - aspectos socioeconómicos. Culturas nacionales. Antropología cultural.

\section{Izalco, la historia de dos pueblos}

Izalco, es un municipio del departamento de Sonsonate. Su nombre proviene de la palabra náhuat Ytzcalco, que etimológicamente significa 'la ciudad de las casas de obsidiana' (Lardé y Larín, 2000).

En los primeros años de la colonia, Izalco, o Ytzcalco, como era conocido por los españoles, fue un solo pueblo. Para finales del siglo XVI, y por influencia de la Iglesia católica, pasó a llamarse Asunción Izalco, obteniendo el título de Villa en 1580 dado por el rey de España Felipe II (Leiva Masin, 2000). Sin embargo, en 1716 se dividió en Dolores Izalco y Asunción Izalco. La decisión de esta división fue tomada por la Iglesia católica, con el argumento de que Asunción Izalco estaba sobrepoblada. Dolores Izalco se declaró oficialmente pueblo en 1719, con la erección de su propia iglesia en tiempos del obispo Juan Bautista Álvarez de Toledo (Leiva Cea, 2007). Dicha iglesia fue la primera estructura que evidenció la diferenciación social entre ambos pueblos.

En 1824, tras emitirse la primera Constitución Política de El Salvador, los pueblos de Dolores Izalco y Asunción Izalco se incluyeron en el distrito y departamento de Sonsonate. Ambos pueblos habían permanecido separados legal y socioculturalmente desde su fundación hasta que, en 1838, por Decreto Legislativo, se fusionaron en uno solo (Lardé y Larín, 2000). El desagrado que provocó dicha unión generó que en 1853 vecinos de Asunción Izalco solicitaran a las Cámaras Legislativas la creación de una municipalidad propia, argumentando que la unión con Dolores Izalco les era perjudicial. Tras una serie de indagaciones, el Órgano Ejecutivo Nacional acordó separar a los dos pueblos nuevamente (Larde y Larín, 2000). Tal decisión system based on the gift through which they ensure their survival.

\section{Keywords}

Cofradías (religious brotherhoods)- Izalco, El Salvador - socioeconomic aspects. Cultural Identity - Izalco, EI Salvador - socioeconomic aspects. National cultures. Cultural anthropology.

fue bien recibida por la comunidad, que, al verse separada nuevamente, se llenó de satisfacción.

Sin embargo, poco fue el tiempo que duro esta separación, ya que el 7 de febrero de 1862 se emitió el Decreto Senatorial en el cual se estableció que las villas de Dolores Izalco y Asunción Izalco se elevaran conjuntamente a la categoría de ciudad, siendo dirigidas por una misma municipalidad. El 18 de febrero de 1869, en la administración del presidente Francisco Dueñas, se reforzó por decreto legislativo la unión de los dos pueblos en un solo gobierno municipal (Lardé y Larín, 2000). En la actualidad, ambos pueblos conforman la ciudad de Izalco. Si bien es cierto al principio dicha unión generaba pugnas entre sus habitantes, con el pasar de los años la confrontación ha perdido fuerza, dando paso a la armonía.

\section{Las cofradías: una estructura social y religiosa de la Colonia}

Las cofradías surgieron en Europa como una institución que además de cumplir con objetivos religiosos tenían funciones de socorro. En la Nueva España, las primeras cofradías fueron creadas por los religiosos franciscanos que se establecieron en la región; unas estaban compuestas por españoles, y otras, por los indígenas de la zona. Estas últimas tenían la labor de promover la celebridad del santo y mejorar el control hacia los indígenas, ampliando así la cristianización (Leiva Masin, 2011).

En las cofradías se proporcionaba amorosamente la doctrina cristiana, se alentaba a la caridad y se concedían indulgencias. "Pero fue la devoción a los santos y a sus fiestas, muy encajadas con la costumbre y calendario 
indígenas, lo que llamaron más poderosamente la atención de los conquistados" (Montes, 1977), que, guiados por la motivación aceptaron finalmente la religión cristiana.

Por otra parte, Leiva Masin (2011) afirma que las cofradías, además de permitir la creación de una nueva estructura social y religiosa, garantizaba un ambiente de seguridad y un sentimiento activo de identidad colectiva. Esta forma de integración y reunión social aseguro la pervivencia de las tradiciones indígenas pese al proceso de asimilación de una nueva cultura y una nueva economía (Montes, 1977).

Paralelo a la institución de las cofradías surgieron los guachivales, estos eran cofradías informales que, si bien habían sido fomentadas por los religiosos regulares, no contaban con una constitución legal (Escalante Arce, 1992). Asimismo, eran de naturaleza individual o privada, carecían de erección canónica y se regían principalmente por la costumbre (Montes, 1977).
Cortés y Larraz, tras su visita por las provincias, se escandalizo al presenciar la organización de cofradías y guachivales; según su percepción, dichas fiestas se realizaban con la mera intención de comer hasta la saciedad, beber hasta la borrachera y bailar hasta el cansancio. Sin embargo, lejos de llevar a los participantes a considerar sus faltas y pecados, las cofradías les hacían sentirse amparados, consolados y solidarios alrededor de una imagen que respetaban y veneraban porque jamás despreciaría a los 'pobres indios', sino, al contrario, se alegraba de que ellos, en la fiesta, estuviesen felices y despreocupados (Escalante Arce, 1992).

En la actualidad, Izalco es considerado como el municipio donde existen más cofradías, celebrándose un aproximado de 38 anualmente. De estas, solamente 22 son consideradas por la población como cofradías tradicionales.

Según el Reglamento Interno de la Alcaldía del Común de Asunción Itzalco, las 22 cofradías tradicionales se dividen de la siguiente manera:

Tabla 1

Mesas altares mayores y menores que pertenecen al orden comunal

\begin{tabular}{cccc}
\hline \multicolumn{2}{c}{ Asunción Izalco } & \multicolumn{2}{c}{ Dolores Izalco } \\
\hline $\begin{array}{c}\text { Mesa altar } \\
\text { San Sebastián Mártir }\end{array}$ & Fecha & Mesa altar & Fecha \\
Jesucito & Cuaresma / Día móvil & Jesús Nazareno & Cuaresma y Semana Santa \\
Padre eterno & Día de la Santísima Trinidad & Justo Juez & 11 -12 de marzo \\
San Juan Bautista & $23-24$ de junio & Nuestro Amo Santísimo & Jueves Santo \\
María Asunción de Agosto & 8,15 y 16 de agosto & San Nicolás de Tolentino & 9-10 de septiembre \\
Santa Rosa de Lima & $28-29$ de agosto & Virgen de los Dolores & 14 y 15 de septiembre \\
San Miguel Arcángel & 28 y 29 de septiembre & Santa Teresa de Jesús & 14 y 15 de octubre \\
San Francisco de Asís & 03 y 04 de octubre & Santa Bárbara & 4 de diciembre \\
San Diego de Alcalá & 11 y 12 de noviembre & Virgen de Concepción & $7-9$ de diciembre \\
Virgen de los Remedios & $9-15$ de noviembre & Santa Lucía & 12 y 13 de diciembre \\
Virgen de Belén & $23-25$ de diciembre & Niño Dios de los Inocentes & 27 al 29 de diciembre
\end{tabular}

Según lo expuesto por la Alcaldía del Común, se presentan las 22 mesas altares, entre ellas, mayores y menores. Siendo las mesas altares mayores: Padre Eterno, María Asunción, Virgen de los Remedios y Jesús Nazareno. Elaboración propia. 


\section{El don en las cofradías de Izalco}

Desde la perspectiva de la antropología económica, el sistema económico adoptado por los miembros de las cofradías es un ejemplo del sistema de dones contractuales desarrollado por Marcel Mauss en su obra el Ensayo sobre el don.

Mauss (1979; citado en Reyes García, 2016) definió el don como "un regalo que conduce a la acción recíproca". Asimismo, para Godelier (1998) es un "acto voluntario, individual o colectivo, que pueden o no haber solicitado aquel, aquellas o aquellos que lo reciben". Constituye un sistema de prestaciones en el que los involucrados están obligados a sumarse a una cadena de intercambios, en la que los individuos interactuantes devuelven lo otorgado. Este sistema conforma la base sobre la que se ha creado la moral del don (Mauss, 2009).

La teoría del don sostiene la existencia de un principio humano: la obligación de dar, recibir y devolver. Para Mauss (citado en Molina y Valenzuela, 2006), "el don y el contradon están impresos en la psique humana: se cambian las cosas no por lo que valen, sino por lo que vale el cambio: la alianza, la solidaridad, la socialidad".

El don tiene la capacidad de aproximar a los protagonistas porque se constituye en reparto, y los aleja socialmente porque hace de uno el deudor del otro (Godelier, 1998). El carácter voluntario, aparentemente libre y gratuito de los dones, en realidad es obligatorio e interesado (Mauss, 2009). A su vez, los movimientos que tienen lugar dentro del sistema de prestaciones generan que los individuos involucrados se unan con creciente intensidad en un vínculo indisoluble de solidaridad constante (Puglia, 2010).

\section{Método}

Para realizar esta investigación, se hizo uso del método cualitativo que, según Sampieri Hernández, Collado Fernández \& Lucio Baptista (2014), trata de "comprender los fenómenos, explorándolos desde la perspectiva de los participantes en un ambiente natural y en relación con su contexto". Como parte del proceso de investigación, se hizo uso del enfoque etnográfico, el cual permite la descripción de un grupo social a partir del trabajo de campo.
En ese sentido, cabe mencionar que fue indispensable realizar múltiples visitas al municipio durante un año, tiempo en el cual se adquirió la confianza de la comunidad, se recolectó información mediante la observación participante en cofradías, $y$, finalmente, se hicieron entrevistas semiestructuradas a los participantes que cumplían con los criterios de selección previamente establecidos.

\section{Participantes}

Los participantes escogidos para la investigación fueron los asistentes a las cofradías del municipio, entre ellos mayordomos/as, cocineras, músicos y colaboradores reconocidos por la comunidad. Además, se contó con la colaboración de los miembros de la Alcaldía del Común.

\section{Tipo de estudio}

El diseño del estudio fue de tipo descriptivo, observacional y etnográfico.

\section{Procesamiento de la información}

Para realizar el análisis de los resultados, se optó por utilizar el software especializado para investigación cualitativa NVivo 11, que facilitó la codificación de los recursos. Se realizó el análisis de los datos mediante nubes de palabras, mapas de jerarquías y conglomerados, a partir de los cuales fue posible conocer ideas, conceptos y relaciones que giran en torno a las cofradías del municipio de Izalco.

\section{Resultados}

\section{Sistema económico de las cofradías del municipio de Izalco}

El sistema económico de las cofradías es reconocido como una cadena de intercambios, que funciona en primer lugar mediante la colaboración voluntaria de amigos y familiares y, posteriormente, con la entrega de un presente, que constituye una forma de agradecimiento de los mayordomos a sus colaboradores, En otras palabras, es una economía basada en el don. Según Firth (citado en Godelier, 1998), el intercambio recíproco de bienes esta mediado por un principio general que designa que todo don debe ser devuelto con un contradon de un valor, como mínimo, igual. 


\section{Figura 1. Mapa de jerarquía sobre el sistema económico de las cofradías de Izalco}

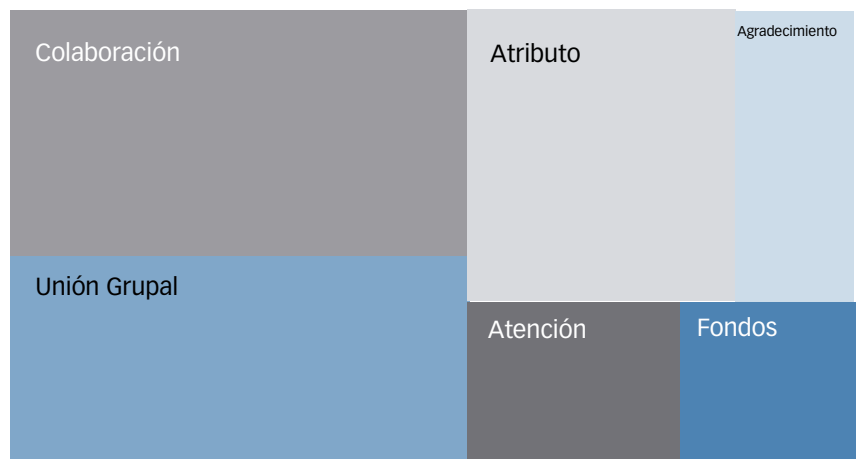

La unión grupal es fundamental en este intercambio de dones, ya que la colaboración es solicitada a los miembros de la comunidad más cercanos al mayordomo. Chanial (2008; citado en Bey, 2011) asegura que "en y por el don se afirman conjuntamente la autonomía personal del sujeto y su pertenencia social; en y por el don se articulan la búsqueda de la ventaja individual y la apertura al otro a través de actos generosos".

Para don Felipe Musto (2018), actual mayordomo de la cofradía de Santa Lucía, es la gente que colabora la que hace posible que la fiesta se realice:

Si la gente no viene, no somos nada. (...) Con un poquito que nos traigan ya es una ayudita. Si usted dice "yo le voy a entregar algo tal día de la fiesta", aunque sea con un poquito, ¿verdad?, viene a colaborarle a la misma gente; no es para nosotros, es para su misma gente.

Se expone, a nivel general, la configuración del sistema económico de las cofradías del municipio de Izalco. Por medio de un mapa de jerarquías, se observa el mecanismo de la economía de dones que prevale en dicha organización social.

En la figura 1 se observa que a nivel económico lo primordial en la planificación y celebración de una cofradía es la colaboración, la cual tiene relación directa con el atributo, nombre que recibe el apoyo solicitado por los mayordomos a sus amistades, asimismo, se relaciona con la categoría unión grupal, lo cual evidencia que la colaboración llega mediante las buenas relaciones sociales. A su vez, el atributo está relacionado con las categorías agradecimiento, atención, unión grupal, y en menor medida a fondos. La relación entre estas categorías es lo que permite que la cadena de intercambios se desarrolle y continúe.

Por otra parte, la categoría atención está relacionada con unión grupal, atributo y fondos. Como se mencionó anteriormente, la unión del grupo es lo que hace posible la colaboración por los atributos y, por lo tanto, el ingreso de fondos económicos que sostienen la celebración.

Finalmente, fondos está relacionado con las categorías atención, agradecimiento, y en menor medida, con atributo.

El mapa de jerarquía evidencia la relación que existe entre esas categorías y esboza el funcionamiento de la economía del don presente en las cofradías.

\section{Definición de la actual cofradía izalqueña}

La estructura original de las cofradías ha presentado modificaciones significativas que en la actualidad han llevado a la población a asegurar que el término cofradía es empleado únicamente por costumbre. Los mayordomos entrevistados afirman que en estos momentos no existen cofradías en el municipio de Izalco, ya que las tareas y actividades que eran realizadas por un grupo de personas ahora las hace sólo el mayordomo, por lo que en Izalco existen las mesas altares o las mayordomías.

Para don Tito Reyes Pásin (2018), exalcalde del Común, "hablar de cofradías es hablar de pueblos originarios, de nuestras raíces y nuestras tradiciones; es hablar de nuestra historia".

Según la percepción de los participantes de la investigación, las cofradías son consideradas como tradiciones del pueblo que se transmiten de generación en generación. La nube de palabras revela que tradición es el concepto que se repite con mayor frecuencia al hablar de cofradías, seguido por organización y costumbres. 
Figura 2. Nube de palabras "¿Qué es una cofradía?"

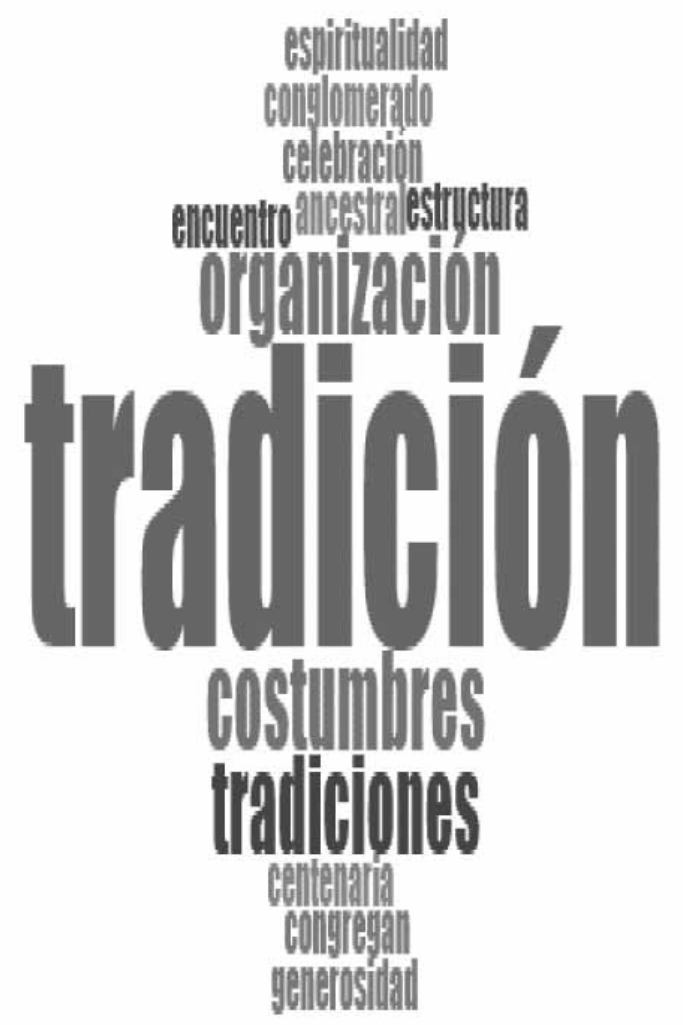

Según Avelar (2018), una cofradía puede definirse como un grupo de personas que se reúnen con el objetivo de celebrar una devoción. Para don Miguel Zetino (2018), actual fiscal de la fiscalía y cofradía las Mariítas, las cofradías son:

Un conglomerado de personas que tratamos de mantener nuestras tradiciones, nuestras costumbres. A través de las cofradías, nosotros mantenemos en el pueblo esa vivencia, porque de eso se trata. Un pueblo sin tradiciones es un pueblo muerto.

En la organización de una cofradía, se observan costumbres ancestrales que sobreviven en la actualidad gracias a la transmisión generacional. Las entradas, los atributos, la música de marimba, la decoración, los rituales, entre otros, forman parte de las costumbres que perviven en las cofradías de la actualidad, impulsadas por el deseo de los mayordomos de replicar el actuar de sus antepasados; $y$ que además existen como evidencia de los pueblos originarios de El Salvador.

\section{Instituciones relacionadas a la celebración de las cofradías}

En la investigación, se indagó sobre la relación que existe entre cofradías-Alcaldía del común, cofradías-alcaldía municipal y cofradías-Iglesia católica. Se presentan de manera individual dado el origen de cada una.

\section{Alcaldía del Común}

Con la masacre de 1932, la Alcaldía del Común perdió el poder político que le había sido otorgado desde el momento de su fundación, sobreviviendo casi totalmente como una institución con funciones simbólicas y folklóricas (Leiva Masin, 2011).

La Alcaldía del Común es la única alcaldía indígena de El Salvador. Sobrevive con la finalidad de velar por la unidad de la comunidad indígena y vigilar el cumplimiento de los usos y costumbres indígenas durante las celebraciones (RodríguezHerrera, 2007), además funge como representante de la comunidad indígena y vela por el bienestar de las cofradías.

Las cofradías, con respecto a la Alcaldía del Común, cumplen con la función de elegir al alcalde del común. La elección está establecida en el Reglamento Interno de la Alcaldía del Común de Asunción Itzalco. La toma de posesión del cargo como alcalde del común se realiza el 31 de diciembre y tiene una duración de dos años. El candidato es propuesto por las mesas altares mayores Padre Eterno y María Asunción, y es aprobado por el consejo de mayordomos que, según el reglamento, tiene voz y voto (Peretti, 2002 citado en Erquicia \& Herrera 2010). Para don Tito Pásin (2009), exalcalde del común, la figura del alcalde del común tiene como objetivo colaborar con la comunidad:

El alcalde del común no es el que manda más, es el servidor, principal de la comunidad, es un apoyo, es alguien que tiene que estar presto para apoyar a quien lo necesite; no es el que manda en la comunidad.

En el contexto ideal, el alcalde del común debe de visitar las imágenes de las cofradías, comunicarse con los mayordomos, conocer sus dificultades y apoyarlos en la celebración de la fiesta. Y, sobre todo, mantener la unión de la comunidad. 


\section{Alcaldía municipal}

El programa 4 del Plan estratégico participativo 2015-2020 del municipio de Izalco se denomina "Fomento de la cultura en el municipio de Izalco". Uno de los objetivos de dicho programa es "promover la riqueza cultural de Izalco como un patrimonio del mismo, integrando a la población originaria con la no originaria" (Consejo municipal, 2014). Además, con el programa, la alcaldía municipal se compromete a continuar brindando el apoyo anual a todas las cofradías del municipio, como parte del fomento a la cultura de los pueblos originarios.

El apoyo anual que brinda la alcaldía municipal a las cofradías es de naturaleza económica, y consiste en la aportación de 100.00 dólares para las cofradías, 200.00 para las cofradías con tronos y 500.00 para las hermandades. Asimismo, colaboran para la fiesta pagando un día de música de marimba de arco.

\section{Iglesia católica}

En la actualidad, las cofradías son organizaciones que forman parte de la religiosidad popular, configurándose en el pueblo y manifestando su pensamiento (López Martínez, 1997). Para Hidalgo Torres (2013), la religiosidad popular permite recorrer un terreno en el que lo sagrado se entremezcla con lo profano; es el momento en el que los pueblos hacen suyo a Dios o a los santos. Lo sacro es leído en términos del pueblo.

Muchas de las practicas realizadas en las cofradías no se corresponden con la fe católica, por lo que, a pesar de ser instituciones religiosas, no forman parte de la Iglesia católica y su relación no es más que el resultado de un proceso histórico. Para los entrevistados, las cofradías son organizaciones que no pertenecen a la Iglesia, ya que los santos y sus costumbres son manifestaciones del pueblo. Alonso García Quele (2018) manifiesta su percepción sobre la relación que existe entre ambas instituciones:

Las mesas altares son independientes de la Iglesia católica; estas son propiedad de la comunidad indígena. Que hay una participación eclesiástica sí, pero es autónoma. La responsable y directora de estas cosas es la comunidad, representada por sus mayordomos.

Los entrevistados concuerdan con que no ha existido una relación directa y palpable, entre cofradías e Iglesia católica, más allá de cumplir con el día de la misa, que es un requerimiento importante de la celebración a la imagen devocional. Asimismo, manifestaron el rechazo de miembros y representantes de la Iglesia católica al considerar que sus costumbres están alejadas de las enseñadas por dicha institución.

Para el párroco Mario Alvarenga, las prácticas que se viven en las cofradías son parte de la identidad cultural de los izalqueños, y por lo tanto es fundamental preservarlas:

Nosotros, como Iglesia, somos muy respetuosos. vemos que ya es parte de la identidad de un pueblo y que no debemos destruirlo, sino que, al contrario, potenciarlo, promoverlo y ayudar en lo que esté a nuestro alcance (Alvarenga, 2018).

Por otra parte, cabe recalcar que el municipio de Izalco cuenta con dos iglesias católicas: Nuestra Señora de la Asunción y Nuestra Señora de los Dolores. Las misas para los santos de las cofradías se realizan en las parroquias de su jurisdicción; $y$, además, por derecho consuetudinario, los santos que pertenecen a un determinado barrio no pueden trasladarse a otro barrio. Por ejemplo, la imagen de la Virgen Santa Teresa de Jesús pertenece al barrio Santa Teresa. $Y$ al ser necesario el cambio de mayordomo, este debe de vivir en dicho barrio. Por lo tanto, la misa se continuará recibiendo en la parroquia Nuestra Señora de los Dolores.

\section{Factores que influyen en la pervivencia de la celebración}

Se evidenció que las condiciones económicas de los mayordomos no constituyen un factor determinante para la celebración de la cofradía, ya que existen otros factores que motivan tanto al mayordomo como a la población para darle continuidad a la fiesta.

En la nube de palabras, se exponen los conceptos más frecuentes en el discurso de los entrevistados acerca de los motivos que los llevan a celebrar la cofradía, pese a las dificultades que se presentan. Los conceptos comunidad y tradición sobresalen como los elementos más influyentes en la preservación de la celebración. Para los mayordomos, la razón principal por el cual se realiza la fiesta es el apoyo de la comunidad, que mediante los atributos contribuyen económicamente; a su vez, lo que motiva a los colaboradores es darle continuidad a la tradición, empujados por el 
sentimiento de compromiso que los lleva a replicar y transmitir las prácticas y conocimientos de sus antepasados.

Por otra parte, la fe y la devoción a los santos influyen en las personas que con humildad y con deseos de apoyar se acercan a las cofradías.

\section{Figura 3. Nube de palabras "Motivaciones que giran en torno a la sobrevivencia de las cofradías"}

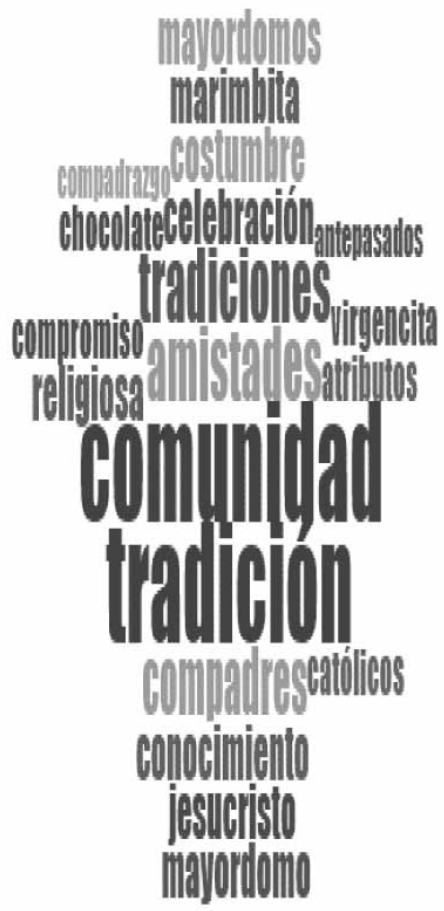

\section{Consideraciones finales}

- Se identificó que en las cofradías de Izalco el aspecto económico no es un condicionante de la celebración, pero, sin embargo, es un factor preocupante.

El atributo, nombre que recibe la colaboración solicitada por los mayordomos a sus amigos y familiares por medio de una tarjeta o invitación, es una parte fundamental del sistema económico de las cofradías, constituido por una interminable cadena de intercambios cuyo fin es sostener la celebración.

La colaboración es producto de la voluntad y del espíritu de servicio de los allegados del mayordomo, que, en la mayoría de los casos, dejan de ir a trabajar los días que dura la celebración. El mayordomo de igual forma, cumple con la responsabilidad de resguardar la imagen sin obtener remuneración por cumplir con dicha labor.

- La cosmovisión de los mayordomos y colaboradores es producto del proceso de enculturación. El sentimiento religioso, transmitido por las generaciones pasadas, sostiene el funcionamiento de las cofradías, ya que, para quienes son parte de ellas, las imágenes de los santos tienen capacidades humanas que les permiten escuchar y ayudar al necesitado, o castigarlo, si fuese necesario.

- La identidad indígena sobrevive en el contexto de las cofradías. Los mayordomos y los colaboradores las reconocen como el patrimonio de sus antepasados, considerando fundamental su preservación, ya que mediante ellas se manifiestan las enseñanzas de los ancestros. La responsabilidad de efectuar la celebración gira en torno al compromiso con sus ancestros, y, por lo tanto, la fiesta se celebra poniendo en práctica lo instruido por sus padres y abuelos.

Sin embargo, la juventud actual no replica las creencias y las prácticas de sus familiares, lo que amenaza la función y existencia de las cofradías.

\section{Referencias}

Alcaldía del Común de Izalco. (s. f.). Reglamento interno. Sonsonate.

Avelar, E. (2017). Cofradías y guachivales. Recuperado de http://www.izalcopiadoso. net/escritos/cofradias.html

Bey, M. (mayo-agosto, 2011). Relaciones sociales: ¿Don 0 intercambio?. Desacatos, (36), 201-208. Recuperado de $\quad$ http://www.scielo.org.mx/scielo.php?script=sci_ arttext\&pid= S1607-050X2011000200014\&lng=es\&tIng=es.

Consejo Municipal. (2014). Plan estratégico participativo del municipio de Izalco 2015-2020. Sonsonate: Alcaldía Municipal de Izalco.

Erquicia Cruz, J. H. y Herrera Reina, M. M. (2010). Aproximación etnográfica al culto popular del hermano Macario en Izalco, Sonsonate, El Salvador. San Salvador: Universidad Tecnológica de El Salvador.

Escalante Arce, P. A. (1992). Códice Sonsonate. San Salvador: Dirección General de Publicaciones e Impresos.

Godelier, M. (1998). El enigma del don. París, Francia: Paidós Ibérica. Hernández Sampieri, R., Fernández Collado, C. y Baptista Lucio, P. (2003). Metodología de la investigación (3a ed.). México, D. F., México: McGraw-Hill Interamericana. 
Hidalgo Torres, A. J. (septiembre, 2013). De cofradías y hermandades en Guatemala (1993-2012). Diálogos, 14(2), 29-76.

Lardé y Larín, J. (2000). El Salvador: Historia de sus pueblos, villas y ciudades. San Salvador: Dirección de Publicaciones e Impresos.

Leiva Cea, C. (2007). El rostro del sincretismo: Guía al plano místico de los antiguos izalcos. San Salvador: Dirección de publicaciones e impresos.

Leiva Masin, J. (2011). Los izalcos: Testimonio de un indígena. San Salvador: Editorial Universitaria.

López Martín, J. (1997). Las hermandades y cofradías en la vida de la iglesia. Fundamentación teológica de la religiosidad popular. Jornadas de religiosidad popular, 199-215.

Mauss, M. (2009). Ensayo sobre el don: Forma y función del intercambio en las sociedades arcaicas. Buenos Aires, Argentina: Katz Editores.
Molina, J. L. y Valenzuela, H. (2006). Invitación a la antropología económica. Barcelona, España: Ediciones Bellaterra.

Montes, S. (1977). Etnohistoria de El Salvador: El guachival centroamericano. San Salvador: Ministerio de Educación, Dirección de Publicaciones.

Puglia, M. (2010). Marcel Mauss: La producción del conocimiento sobre la economía del don. Buenos Aires, Argentina: Universidad Nacional de La Plata.

Reyes García, H. A. (enero-abril, 2016). Dar, recibir y devolver: El reconocimiento del don entre los chaa tatna y los chaa tasi de la Mixteca Alt. Cuicuilco, 23(65), 101-116.

Rodríguez-Herrera, A. (2007). Agua e identidad étnica en Izalco, República de El Salvador. Agricultura, Sociedad y Desarrollo, 4(2), 83-103. 